\title{
A lógica econômica global e a revisão do Welfare State: a urgência de um novo pacto
}

\section{GILBERTO DUPAS}

A PARTIR DAS REFORMAS neoliberais, as questões centrais envolvendo as relações entre a sociedade e os Estados nacionais têm a ver com a capacidade desses futuros Estados de assumir eficientemente seu novo papel indutornormativo-regulador, ao mesmo tempo em que um original pacto social consiga definir como lidar com a tendência de crescente exclusão social decorrente do atual modelo econômico global.

A internacionalização dos agente econômicos privados e a privatização dos serviços públicos de infra-estrutura, além de trazer claros benefícios à eficiência econômica da produção, têm gerado tendência simultânea de aumento do desemprego formal e crescente flexibilização da mão-de-obra, como constatado em pesquisa que conduzimos atualmente no Instituto de Estudos Avançados da USP (1). Em decorrência, os governos inevitavelmente acabam pressionados a garantir certa proteção social às crescentes populações carentes, em contradição com seus recursos fragilizados pela meta imperiosa de equilíbrio orçamentário.

Um novo pacto para o desenvolvimento exigirá uma profunda reflexão sobre a natureza das novas relações entre o Estado, a sociedade civil e o setor privado, bem como a disposição dessas sociedades em eleger prioridades que poderão, por vezes, conflitar com o primado absoluto do mercado.

Assim, as tendências do cenário internacional têm provocado a necessidade de uma profunda revisão no papel do Estado moderno. Após ampla aceitação do esgotamento das possibilidades de manutenção das práticas keynesianas, o debate acabou se balizando entre a idéia de um Estado mínimo - que não crie embaraço algum ao mercado - e de um Estado forte - que saiba atuar no mundo globalizado minimizando seus conflitos, inclusive a exclusão social.

Recente relatório do Banco Mundial (2) aponta quatro principais razões para a preocupação generalizada sobre a redefinição e os limites do novo Estado: a explosão das economias socialistas; a crise fiscal do Welfare State em significativa parte das economias desenvolvidas; o colapso dos Estados e a explosão de emergências humanitárias, notadamente nos países em desenvolvimento; e o papel importante do Estado nas economias asiáticas (3). Certamente, a nova percepção do fenômeno da exclusão social é uma destas emergências humanitárias. 
Diz o citado relatório: "Assim como nos anos 40, a atenção recentemente dada ao papel do Estado foi inspirada por eventos dramáticos na economia global, que têm modificado drasticamente o ambiente no qual os Estados operam. A integração global das economias e a difusão da democracia reduziu o espaço para políticas arbitrárias. Impostos, regras de investimento e políticas econômicas têm que responder às normas da economia globalizada. As mudanças tecnológicas abriram novas oportunidades de serviços sem fronteiras e ampliaram o papel dos mercados. Estas mudanças têm significado novos e diferentes papéis para os governos - não mais como provedores, mas como facilitadores e reguladores (...). O desenvolvimento econômico e social sustentável é impossível sem um Estado atuante. Tem se tornado crescentemente consensual a idéia de que um Estado atuante - e não um Estado mínimo - é central ao desenvolvimento econômico e social, ainda que como parceiro e facilitador do que como um diretor."

Essa derradeira posição do Banco Mundial parece ter implicado a revisão de conceitos mais liberais que caracterizaram as recomendações dessa instituição até recentemente. Não se trata mais de reduzir radicalmente o papel do Estado, mas de modificá-lo profundamente, transformando-o e fortalecendo-o para novos papéis fundamentais.

A última publicação da International Labour Organization (4) aponta para a mesma direção. Anuncia como cada vez mais importante o papel do Estado em um mundo globalizado: "Economistas tendem a pensar no mercado e no governo como substitutos. Boa parte das intervenções do governo são vistas como inimigas à operação dos mercados. Por outro lado, a expansão dos mercados é percebida como prejudicial à efetividade das ações governamentais - nos níveis macro e microeconômicos. Contrariamente ao que muitos economistas poderiam esperar, o escopo de ação do governo tem crescido, e não diminuído. Com efeito, reduzir as dimensões do Estado - o que tem sido uma tendência dos anos 90 - pode ameaçar a manutenção do livre comércio em escala global. A globalização requer grandes, e não pequenos governos."

É nesse novo contexto que cabe questionar o discurso que predominou nesta década, intitulado por muitos como "o fim do Welfare State". Ele foi exaustivamente enunciado por intelectuais e políticos das economias chamadas desenvolvidas - lideradas pelos EUA - e que, com efeitos muito mais deletérios, acabou sendo importado pelos países da América Latina. De eficaz, ficou o longo ciclo de privatizações - em curso - que indica o possível aprimoramento da infra-estrutura de vários países periféricos - incluindo, supostamente, a queda de suas tarifas - e a saída progressiva dos Estados como produtores de bens e serviços privados. E, como conseqüência, um provável alívio dos caixas de seus Tesouros, delapidados pelos déficits recorrentes de suas empresas estatais ineficientes. Permanece urgente, pois, a necessidade de construir - de maneira eficaz - o novo Estado indutornormativo-regulador, apto a enfrentar sua enorme e indelegável missão de viabilizador de serviços públicos essenciais à população de baixa renda nas áreas de saúde, educação, habitação e amparo à exclusão social. 


\section{O fim do Welfare State?}

A primeira dificuldade para quem tenta investigar a natureza da discussão sobre "o fim do Welfare State", é descobrir como os praticantes desse discurso definem Welfare State. Artigo recente publicado em The Economist sobre o tema, que causou certo impacto, faz a seguinte provocação: "Quem disse que a era dos grandes governos terminou?" A descoberta interessante do estudo é que, em todas as economias avançadas, os gastos do governo têm crescido, e rapidamente, como porcentagem do produto nacional bruto (PNB). Nos países desenvolvidos, sua média manteve-se em vigorosa ascenção: 27,9\% (1960), 42,6\% (1980), 44,8\% (1990) e 45,9\% (1996). Dentre esses países, EUA e Japão têm as menores proporções de gastos de governo com relação ao seu PNB (33\% e 36\%, respectivamente, em 1996). No entanto, neles também se observaram taxas crescentes de 1960 a 1996. Portanto, em plena era da globalização e do discurso neoliberal sobre o Estado, a participação dos gastos do governo no produto nacional continua a aumentar.

Torna-se necessário, porém, analisar a composição desses gastos para captar o sentido de tais transformações. O artigo citado divide o total de despesas públicas em quatro grandes categorias: consumo do governo (o valor que o Estado, enquanto provedor de serviços, paga em salários e outros insumos); investimentos públicos; transferências; e subsídios e juros da dívida nacional (interna e externa). A parcela de investimentos públicos foi a única que teve queda significativa de 1960 a 1990 - o que não surpreende, face à onda de privatizações que varreu esses países desde a década de 70 . Todas as outras categorias de gastos mostraram significativos aumentos, principalmente os juros sobre a dívida. $\mathrm{O}$ que não deixa de ser curioso, já que o pressuposto do fim do Estado keynesiano é, justamente, o controle do déficit público. O exame dos dados mostra que o item médio mais significativo de gastos do governo são as transferências e subsídios, o qual cresceu de 6\% do PNB em 1960 para quase 25\% em 1990. Ao que tudo indica, os Estados nacionais continuam não somente gastando muito, como se endividando crescentemente para pagar estes gastos.

Os dados analisados por Dumont (5) vão na mesma direção. Em todos os países da Europa ocorreu, como proporção do PIB, acentuado aumento das despesas de proteção social desde os anos 70 até 1992. É o que mostra a tabela 1.

As análises do Word Development Report 1997 confirmam as mesmas tendências para o aumento dos gastos dos governos dos países da OECD a partir dos anos 80. Juros, tranferências e subsídios também cresceram significativamente nos últimos anos para os países do Oriente Médio, da África, da Ásia, do Pacífico, da América Latina e do Caribe, como pode visualizado nos gráficos 1 e 2.

O citado World Labor Report 1997 (1998) vai além e quer demonstrar uma conexão entre a abertura econômica, que caracterizaria a globalização, e o nível de consumo do governo. O gráfico 3 tenta evidenciar uma relação positiva entre o nível de abertura econômica e os welfare transfers. A justificativa seria razoavelmente intuitiva: os crescentes gastos do governo serviriam para mitigar os riscos 
crescentes da maior exposição das economias à competição externa. De acordo com o relatório: "Com crescentes competição e insegurança no trabalho, os trabalhadores irão depender mais de recursos estáveis para seguro-desemprego, educação e treinamento nos próximos anos. Na ausência destas políticas e de programas governamentais, o suporte político para a globalização seria erodido.”

Tabela 1 - Despesas de proteção social

\begin{tabular}{lcccc} 
& & \multicolumn{2}{c}{ (Em \% do PIB) } \\
\hline País & 1970 & 1983 & 1989 & 1992 \\
\hline Paises Baixos & 19,60 & 33,47 & 31,00 & 32,00 \\
Dinamarca & 19,60 & 30,10 & 29,90 & 31,40 \\
França & 18,90 & 28,30 & 27,50 & 29,20 \\
Luxemburgo & 15,60 & 27,30 & 25,20 & 28,00 \\
Bélgica & 18,70 & 30,80 & 26,70 & 27,80 \\
Alemanha & 21,50 & 28,80 & 27,50 & 27,30 \\
Reino Unido & 14,30 & 23,90 & 21,70 & 27,20 \\
Itália & 14,40 & 22,90 & 23,10 & 25,60 \\
Espanha & 10,00 & 19,50 & 20,00 & 22,50 \\
Irlanda & 13,70 & 24,10 & 19,70 & 21,60 \\
Grécia & 7,60 & 17,40 & 20,80 & 19,30 \\
Portugal & 9,10 & 14,10 & 14,50 & 17,60 \\
\hline
\end{tabular}

Fonte: Les systèmes de protection sociale en Europe. Jean-Pierre Dumont, 1995.

Embora interessante como hipótese, essa conclusão nos parece prematura. Seria preciso uma análise mais profunda da natureza dos gastos e da qualidade do seu output para testar a solidez da hipótese.

Se não está ocorrendo uma redução das despesas de proteção social na Europa, nos EUA ou no Japão - como os dados do gráfico 3 sugerem - e se os gastos públicos aumentam na grande maioria dos países do mundo, por outro lado tem havido uma inequívoca onda de pregação desestatizante. $\mathrm{O}$ discurso liberal varreu as economias mundiais. No Brasil, a redução das dimensões do Estado tem sido apresentada como capaz de resolver os problemas de um setor público estrangulado por suas dívidas. E a chamada flexibilização do mercado de trabalho - a eliminação de certas garantias sociais dos trabalhadores - é colocada como condição importante para o enfrentamento do desemprego. Ambas as proposições parecem fazer sentido, mas não são socialmente neutras e contêm vários riscos. 
Diante disso, cabe se indagar quais as causas desse discurso liberalizante e investigar suas possíveis relações com o processo de globalização da economia.
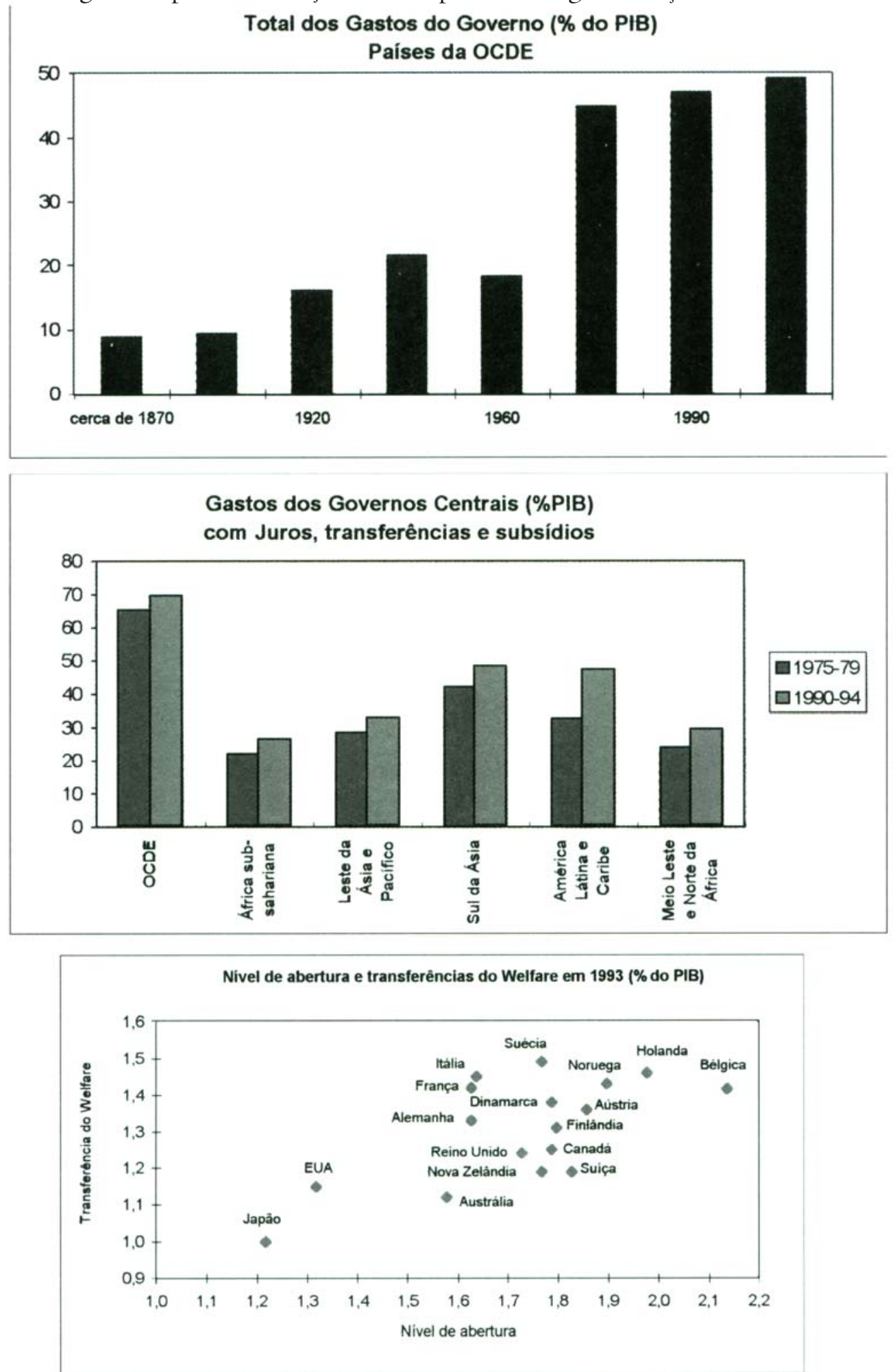

Fonte: World Labour Report, 1997/98. Industrial relations, democracy and social stability. 


\section{As origens do discurso liberalizante}

Przeworski \& Wallerstein (6) atribuem o que chamam de "ofensiva de direita" a uma crise de financiamento do Estado iniciada na década de 70, após o primeiro choque do petróleo. Ela teria abalado o verdadeiro compromisso keynesiano de "democracia capitalista". Nas palavras dos autores: "Até o final dos anos 60, o keynesianismo foi a ideologia oficial do compromisso de classe, sob a qual diferentes grupos podiam entrar em conflito nos limites de um sistema capitalista e democrático. (...) A crise do keynesianismo é uma crise do capitalismo democrático.”

De fato, o keynesianismo manteve, desde o pós-guerra, a expectativa de que o Estado poderia harmonizar a propriedade privada dos meios de produção com a gestão democrática da economia. Acabou fornecendo as bases para um compromisso de classe, ao oferecer aos partidos políticos representantes dos trabalhadores uma justificativa para exercer o governo em sociedades capitalistas, abraçando as metas de pleno emprego e da redistribuição de renda a favor do consumo popular. O Estado provedor de serviços sociais e regulador de mercado tornava-se mediador das relações - e dos conflitos - sociais.

A “crise do keynesianismo" é, na verdade, a crise das políticas de administração de demanda: quando há sinais de insuficiência de capital, políticas voltadas à eliminação do hiato entre produção corrente e produção potencial não mais fornecem solução. Essa situação tornou-se mais nítida a partir dos anos iniciais da década de 70 , quando se desenhou um quadro de inflação com baixas taxas de crescimento econômico. Surgiram, então, tentativas de substituir políticas de demanda por outras de oferta. A redistribuição da renda a favor dos lucros apareceu como um custo que a sociedade deveria suportar para obter taxas de investimento mais altas. Para Przeworski \& Wallerstein, "a manutenção do Pleno Emprego acabou sendo uma das principais barreiras ao investimento que melhoraria a produtividade, aumentaria a produção, elevaria os salários e/ou reduziria a jornada de trabalho. (...) Pela primeira vez em muitas décadas, a direita tem um projeto histórico próprio: libertar a acumulação de todas as cadeias impostas a ela pela democracia.”

Nessa perspectiva, o mercado tendeu a ser reabilitado como instância reguladora por excelência das relações econômicas e sociais no capitalismo contemporâneo. A ele caberia determinar, inclusive, o tipo e a quantidade de investimento da economia, decisão privada com profundos impactos públicos.

O vácuo teórico e a incapacidade de gestão dos Estados nacionais, fenômenos que se seguiram à crise pós-keynesiana, abriram espaço para os sempre ardorosos defensores do Estado mínimo. A idéia de que o Estado tende intrinsecamente à ineficiência voltou com toda força nos discursos mais conservadores quando se evidenciaram os problemas de financiamento e gestão dos governos nos países desenvolvidos.

Drucker (7), invocando argumento de Adam Smith - pai do liberalismo clássico - nos faz uma divertida analogia entre o Estado e a figura pesada e sem agilida- 
de de um elefante: “ Smith tinha pouco apreço por homens de negócio e menos ainda por individualismos. (Ainda assim), ele não argumentava que o governo não conduzisse bem a economia. Ele dizia que o governo, por sua própria natureza, simplesmente não poderia conduzi-la. Ele não argumentava que elefantes não voavam tão bem quanto andorinhas. Ele argumentava que governos, sendo elefantes, não podiam voar."

Para Drucker, o ano de 1973, com o choque do petróleo e o estabelecimento de taxas de câmbio flutuantes, teria marcado o fim da longa era Roosevelt e o início da inevitável conscientização acerca dos limites do Estado. A crise econômica generalizada que se seguiu ao choque do petróleo - com desequilíbrios nos balanços de pagamento, inflação e medíocres taxas de crescimento - mostrou ao mundo que os governos tinham limites muito mais estreitos do que se imaginava até então para a condução da política econômica. Mais do que isso: qualquer ação (que se traduzisse em gastos do governo) poderia ser ainda mais nociva à economia, exacerbando a tendência à inflação.

Ao governo caberia tão somente o monopólio da defesa e das armas nacionais, a garantia da manutenção das leis, da ordem, da justiça e da segurança, e o estabelecimento de um level playing field - um conjunto de regras básicas que permitissem aos agentes econômicos se movimentarem livremente. As atividades do governo deveriam ser encaradas como temporárias - sob pena de introduzirem distorções no jogo econômico - e o Estado teria de se retirar assim que organizações não-governamentais - de qualquer espécie - se mostrassem capazes de fazer melhor do que ele.

Drucker citava como exemplo de dois grandes fiascos do governo norteamericano no pós-guerra o programa de moradia para pessoas de baixa renda e as políticas de Welfare. O primeiro deles significou um enorme montante de gastos e teria resultado em habitações "precárias, vandalizadas, sujas e infestadas de ratos". Quanto ao Welfare (que o autor chama de welfare-mess), apesar de ter absorvido enorme volume de dinheiro público, seria pernicioso ao "encorajar a dependência". Nas palavras dele: "De fato, pode-se dizer - e tem sido dito - que os pobres na América, e especialmente os negros pobres, se tornaram mais pobres, mais desamparados, mais desfavorecidos, quanto mais recursos do Welfare foram gastos para ajudá-los. O Welfare americano encoraja a dependência. Paralisa mais do que energiza."

É curioso notar que, no início dos anos 80 , Drucker atribuía às empresas transnacionais - os novos agentes econômicos globais - a condição de serem também os novos agentes sociais da era globalizada: caberia a elas providenciar, desta vez de forma eficiente, os benefícios sociais que os Estados nacionais - fadados ao encolhimento - não conseguiam prover. Essa hipótese rapidamente tornou-se fantasiosa.

Em artigo escrito 15 anos depois (8), muito mais realista, Drucker já reconhece que "o Estado Nacional, apesar do fenômeno da globalização da economia 
mundial, vem revelando surpreendente resistência". O Estado já não é mais um elefante que não pode voar, mas um "sobrevivente de fibra" que deve ter seu papel substancialmente modificado no que tange às políticas fiscais e monetárias internas, às políticas econômicas externas e ao controle das transações internacionais. Drucker acha agora que o fim de Bretton Woods teria dado a esses Estados maior soberania no controle da moeda, da política fiscal e de crédito e - em decorrência maior espaço para dar vazão à sua irresponsabilidade fiscal. No entanto, a nova economia mundial globalizada estaria impondo a eles novas e mais rigorosas restrições. Por um lado, a enorme massa de "dinheiro internacional" oriunda da especulação cambial, apesar de "virtual", seria dona de um poder muito concreto. Esses recursos, detendo enorme volatilidade e mobilidade absoluta, teriam a capacidade de gerar enormes - e reais - desastres econômicos. Ainda antes da crise asiática, mas citando casos de ataques especulativos nos EUA, França e México, ele lembra que, "em todos os casos, o dinheiro virtual levou a melhor, comprovando que a economia global é o árbitro final das políticas monetárias e fiscais “.

Nesse contexto, a única forma de reduzir a vulnerabilidade das economias seriam políticas fiscais e monetárias que evitassem a dependência dos países do volátil dinheiro internacional para empréstimos de curto prazo destinados a cobrir seus déficits. Orçamentos públicos equilibrados seriam condição primordial para a manutenção da ordem econômica neste novo mundo globalizado. Do que chama de "natural irresponsabilidade dos governos", Drucker aplaude a tendência de se restaurarem instituições supranacionais que a eles imponham restrições (a moeda única de CEE seria um avanço neste sentido). Isso apenas, segundo ele, institucionalizaria uma realidade já existente: as decisões econômicas fundamentais estariam sendo tomadas na economia global e por ela, e não pelos Estados nacionais. Ainda segundo Drucker, essa perda de autonomia fiscal e monetária poderia, paradoxalmente, tornar os Estados nacionais mais fortes ao impedi-los de se aventurarem em gastos supérfluos.

Já Hirst \& Thompson (9), procuram mostrar que a crise do "keynesianismo nacional", a partir dos anos 70, teve seus impactos magnificados pelo processo de globalização da economia. Com efeito, as "políticas de demanda" - ou seja, as políticas nacionais voltadas ao incremento da renda e do emprego por meio de políticas fiscal e monetária - teriam como conseqüência uma taxa de inflação superior à dos países competidores. Com isso, haveria uma tendência ao aumento das importações (pelo aumento dos preços internos e da renda nacional), o que levaria a constrangimentos no balanço de pagamentos. Por outro lado, a utilização de instrumentos de política monetária também seria muito dificultada por internacionalização dos mercados financeiros, abolição dos controles das troca e expansão das operações de crédito por parte das instituições financeiras.

Para esses autores, estaria ocorrendo um estrangulamento da capacidade dos Estados nacionais de gerirem seus instrumentos de política econômica. A tudo isso, se aliaria ainda a ausência de um único poder hegemônico capaz de articular e regular a expansão da economia internacional - papel cumprido pelos EUA entre o 
fim da Segunda Guerra Mundial e 1972 - e a falta de capacidade da teoria econômica de justificar, como resultado esperado, políticas expansionistas sustentáveis. Segundo eles, "mercados podem ser internacionais, mas a riqueza e a prosperidade econômica são fenômenos nacionais." Como decorrência, acham inevitável aos Estados nacionais o papel de garantir a construção de uma "coalizão distributiva". Ela estaria baseada na garantia do equilíbrio entre o consumo e o investimento; no comando de um acordo sobre níveis de taxação; no controle - em alguma medida das relações entre capital e trabalho; na orquestração de um "consenso social" (estabelecendo uma "cultura política colaborativa"); e no equacionamento da questão federativa (o equilíbrio fiscal entre diferentes níveis de governo).

Por outras razões, Schlesinger (10) também mostra-se apreensivo quanto ao futuro do Estado nação na era da informação. Ele acha que "o computador transforma o mercado em uma monstruosa máquina maléfica global que rompe todas as fronteiras, (...) negando às nações a possibilidade de moldarem seu próprio destino econômico, (...) criando uma economia mundial sem uma sociedade mundial" e se pergunta: onde pode residir a democracia sem uma autoridade capaz de exercer um controle internacional, uma vez que o Estado nação, sua sede tradicional, está se desmantelando? Se a democracia liberal sobreviveu por um triz ao século $\mathrm{XX}$ - marcado por "guerras, destroçamento de velhas estruturas de segurança e revoluções inflamadas contra a democracia”, Schlesinger acredita que ela corre ainda maiores riscos no século que está prestes a se iniciar.

Há uma outra linha de argumento dos que, por outros caminhos, percebem o Estado progressiva e irremediavelmente incapacitado para exercer papel ativo na condução das políticas de demanda e, em particular, no manejo de variáveis distributivas. É a dos regulacionistas, segundo a qual a cada modo de produção corresponderia um modo de regulação social. Ao modo de produção fordista correspondeu o padrão de consumo de uma estrutura de proteção social incorporada no Welfare State, que em parte sustentava este padrão de consumo. Já o modo de produção enxuto, cuja palavra de ordem é a flexibilidade dos fatores de produção para possibilitar a rápida adaptação da produção às variações da demanda pelo produto, não traz em sua lógica a generalização do consumo de massa e tampouco, por conseguinte, a estruturação de mecanismos de distribuição de renda.

Fiori (11) argumenta que, apesar de já se ter constituído um novo paradigma industrial pós-fordista, ainda há um vácuo quanto ao modelo político-institucional que o acompanhará. Assim, para ele, essa incontestável crise nos Estados nacionais, por estarmos em um "contexto econômico internacional que o fragiliza", talvez ainda não seja terminal. $\mathrm{O}$ que estaria ocorrendo referir-se-ia a um momento de indefinição acerca do que seria um "modo de regulação enxuto".

Ao lado da sensação de que os Estados nacionais têm encontrado óbvios limites à sua atuação - fato lamentado por alguns e louvado por outros -, a idéia de que o capitalismo está entrando em uma nova e revolucionária fase parece ser compartilhada por muitos autores. Neste novo capitalismo "desenfreado", reina 
uma espécie de "lei da selva": só sobrevivem os mais fortes. Dentro desse contexto o discurso que surge, cada vez mais forte, atribui à estrutura do Welfare State o condão de entravar a competitividade das economias. O Estado protetor estabeleceria uma espécie de piso no nível de vida dos cidadãos - e portanto - tornando menos comprimível o custo do fator mão-de-obra justamente no momento em que grandes estoques de reserva de pobreza reduziram de tal modo os salários que reintroduziram o low-wage-factor como forte dado de competição em certas cadeias globais.

Por fim, é importante lembrar o papel desempenhado na imaginação política - não somente dos conservadores mas também da esquerda em todo o mundo pelo fracasso da utopia socialista. A década de 90 iniciou-se, sobre as ruínas do muro de Berlim, entronizando o mercado como instância suprema de coordenação das atividades econômicas e instigando os Estados a bater em retirada não só nas áreas em que - agora comprovadamente - não tinham competência para estar.

Todos esses argumentos explicam a origem do discurso liberalizante. Resta compreeender por que tal discurso não se tornou prática.

\section{Um Estado insistente}

Schlesinger, no artigo já mencionado, aponta para uma das razões fundamentais da insistente permanência do Estado na esfera econômica. O que ele chama "avanço impetuoso do capitalismo" traz ao Estado novas e urgentes demandas. Essa nova economia global teria como subproduto o aumento da desigualdade, com suas "conseqüências desagregadoras". O autor chega a vislumbrar um "proletariado à la Blade Runner", que seria o destino daqueles que não conseguem se adaptar à era da informação e da globalização - uma "subclasse revoltada, amargurada e violenta".

Mesmo sem adotarmos uma visão apocalíptica do capitalismo contemporâneo, é evidente que tem ocorrido, no mundo inteiro, um aumento contínuo das taxas de desemprego. Novas formas de emprego tendem a se desenvolver e substituir as relações tradicionais entre capital e trabalho e a gerar crescimento do setor informal e forte flexibilização do emprego, cujas conseqüências estabilizadoras da oferta total de trabalho ainda não podem se avaliadas. Mas, no momento, o Estado vem sendo chamado em toda parte - e especialmente nos países que possuem uma estrutura de Welfare - a garantir a sobrevivência dos cidadãos que estão sendo expulsos em grande quantidade do mercado formal.

Por outro lado, ocorre claramente o que se poderia chamar "efeito democracia": aumenta o número de desempregados e pobres, crescendo sua base política. Introduz-se, assim, uma dissonância entre o discurso liberalizante das elites e sua praxis política. O resultado das últimas eleições na França é uma amostra desse fenômeno. Cresce a voz dos que clamam por maiores garantias sociais por parte do Estado. 
Somam-se a isso, ainda, situações estruturais decorrentes de fatores demográficos - como o envelhecimento da população, que significa um importante peso adicional aos custos de previdência - e a própria evolução da tecnologia incorporada nos serviços sociais, principalmente nos equipamentos médicos com alta tecnologia e custos elevados. O surgimento de uma doença cara e de perfil epidemiológico assustador como a Aids e as novas resistências de bactérias aos antibióticos usuais também têm o seu papel no surgimento de novos ônus à saúde pública.

Se é inequívoco que os custos associados ao fornecimento de serviços públicos pelos Estados nacionais têm aumentado no mundo todo, o que dizer da eficiência dos serviços prestados? Seria a progressiva diminuição da produtividade relativa dos serviços públicos, ineficientes por natureza, a responsável pela sensação de que, apesar de as despesas dos governos se multiplicarem na área social, a qualidade do out-put estaria cada vez pior e mais defasada da demanda? Esta é mais uma questão importante. Afinal, a lógica intrinsecamente ineficiente das concorrências públicas - numa década em que hardwares e softwares tornam-se obsoletos em alguns meses associada à corrupção e à pouca qualificação quase inevitáveis em grande parte do setor público, estaria condenando definitivamente os Estados a terceirizar-se ou privatizar seus serviços públicos e sociais?

Dumont (12), na obra já citada, mostra sua apreensão com relação a acordos supranacionais como o Tratado de Maastrich. As políticas de harmonização fiscal exigidas pelas rigorosas metas de inflação, déficit e dívida públicos estariam levando, desde 1992, a planos de rigor nos países participantes que atingiriam necessariamente os sistemas de proteção social.

O que se observa, não só na Europa, são acaloradas discussões sobre reformas no plano das instituições. Ao que tudo indica, a direção destas reformas vai no sentido de isentar o Estado dos crescentes custos da exclusão social. Mesmo a Charte Sociale - um primeiro acordo sobre direitos sociais fundamentais acertado em 1989 em Bruxelas - contemplaria, fundamentalmente, direitos sociais dos trabalhadores, mas não dos cidadãos.

No momento, no entanto, parece haver mais uma ameaça de desmantelamento do Welfare na esfera das discussões políticas do que propriamente sua efetivação no plano econômico. Mas a questão quanto ao futuro papel dos Estados nacionais continua em aberto, bem como a crescente disparidade entre as demandas sociais crescentes e a impossibilidade do Estado em atendê-las do modo convencional.

\section{O Estado indutor-normativo-regulador e a urgência de um novo pacto social}

Os Estados nacionais desta virada de século estarão sendo fortemente pressionados em pelo menos duas grandes frentes. A primeira refere-se à conclusão da gigantesca transformação das infra-estruturas nacionais, com seu comando progressivamente deslocado para o setor privado. A lógica privada parece ter amplas 
condições de aumentar a eficiência operacional das ex-empresas estatais. A questão central, porém, é como garantir que essas vantagens cheguem ao consumidor. Para tanto, é preciso garantir forte condição competitiva e um sistema regulatório independente e eficaz. Nos vários casos de monopólio natural, os sistemas regulatórios deverão ser implacáveis, sob pena de ficar-se apenas com as desvantagens da substituição de monopólios públicos por privados. Para tanto, as agências reguladoras devem garantir a presença ativa de representantes da sociedade civil e dos consumidores, além de membros do governo, configurando-se - portanto - como interessantes minilaboratórios de pactos sociais.

A outra grande questão é o crescimento da percepção das sociedades de que o novo modelo global de produção agrava a exclusão social. Essa conclusão é verdadeira, pelo menos quanto às tendências de aumento geral do desemprego formal e da flexibilização do trabalho. Isso tende a aumentar a pressão sobre os Estados nacionais exigindo a retomada de políticas públicas eficazes na área social. As grandes corporações mundiais, fugaz esperança do início dos anos 80 , têm mantido a esse respeito clara posição: seu papel limita-se a melhorar a competitividade para sobreviver, remunerar seus acionistas e, em decorrência, manter os empregos possíveis; e usar, sempre que possível, o low-wage dentro da lógica de suas cadeias produtivas.

Assim, a atual carência de recursos dos governos - comprometidos a zerar seus déficits - somada à ineficiência de máquinas administrativas públicas, nos faz concluir que somente um novo e original acordo entre os governos e as sociedades civis permitirá avançar. Esse novo pacto pressupõe, necessariamente, a recuperação da capacidade de indução de Estados nacionais éticos e fortalecidos em sua legitimidade, e a criação de estruturas eficazes que - com a íntima colaboração da sociedade civil - tenham condição de fiscalizar o cumprimento dos acordos e dos compromissos assumidos nos processos de regulação.

\section{Notas}

1 A nova lógica econômica e a exclusão social, pesquisa conduzida pelo autor na área de Assuntos Internacionais do Instituto de Estudos Avançados da Universidade de São Paulo. Adriana Nunes Ferreira (mestre em economia-USP) colaborou diretamente no tema sobre Welfare State. Vários conceitos desenvolvidos pelo autor em artigos e ensaios recentes sobre globalização, exclusão social e a nova lógica econômica estão incorparados no texto, sem citação.

2 The State in a changing World. World Development Report 1997.

3 Quanto ao importante papel dos Estados nas economias asiáticas, a recente e violenta crise econômica da região encarregou-se de colocar em dúvida mais uma das certezas que orientavam o pensamento econômico atual quanto ao sucesso da Ásia. Ao contrário do senso comum, alguns Estados asiáticos foram fortemente responsabilizados pelo artificialismo e paternalismo que permitiram confundir os critérios rígidos de competitividade da atividade produtiva local, aprofundando a crise. 
4 Industrial relations, democracy and social stability. World Labour Report 1997-1998.

5 Jean-Pierre Dumont, Les Systèmes de Protection Sociale en Europe, 1995.

6 A. Przeworski \& M. Wallerstein, O capitalismo democrático na encruzilhada. Novos Estudos Cebrap, n. 22, 1988.

7 Peter Drucker, The new realities, 1982.

8 Id., A economia global e o Estado nacional. Foreign Affairs, set. 1997.

9 Hirst \& Thompson, Globalization in question: international economic relations and forms of public governance.

10 Arthur Schelesinger Jr., Há futuro para a democracia? Foreign Affairs, set. 1997.

11 J.L. Fiori, Existe um Estado brasileiro pós-fordista? Reforma e funções do Estado brasileiro no novo paradigma industrial.

12 Jean-Pierre Dumont, cit.

Gilberto Dupas é coordenador da Área de Estudos Internacionais do Instituto de Estudos Avançados da USP e professor da FDC no European Institute of Business Administration - Insead (França) e da NorthWestern University - Kellog (EUA), autor de vários livros, entre os quais Crise Econômica e Transição Democrática.

Este texto serviu de referência para recente seminário realizado no Cebrap, dirigido pelo autor. 